\title{
High-level EPA production from Phaeodactylum tricornutum
}

\author{
Yi Cui ${ }^{1}$, Skye Thomas-Hall ${ }^{2}$, Elvis Chua ${ }^{2}$, and Peer Schenk ${ }^{1}$ \\ ${ }^{1}$ University of Queensland \\ ${ }^{2}$ University of Queensland
}

May 5, 2020

\begin{abstract}
Phaeodactylum tricornutum is a lipid-rich marine diatom that contains a high level of omega-3 polyunsaturated fatty acids, especially eicosapentaenoic acid (EPA). In an effort to reduce costs for large-scale cultivation of this microalga, we first established a modified BBM medium (0.3 x strength BBM with $90 \%$ reduced phosphate content) to replace the traditional $\mathrm{F} / 2$ medium. P. tricornutum could grow in extremely low phosphate concentrations $(25 \mu \mathrm{M})$, without compromising the EPA content. In the presence of sea salts, silicate addition was not necessary for high rate growth, high EPA content or lipid accumulation in this species. Using urea as the sole nitrogen source tended to increase EPA contents (by 24.7\%) while not affecting growth performance. The use of sea salts, rather than just sodium chloride led to significantly improved biomass yields (20\% increase) and EPA contents (46-52\% increase), most likely because it supplied sufficient essential elements such as magnesium. A salinity level of $35 \mathrm{ppt}$ led to significantly higher biomass yields compared to $20 \mathrm{ppt}$, but salinity had no significant influence on EPA content that reached high average levels of $51.8 \%$ of total fatty acids during exponential growth phase at 20 ppt in modified BBM medium with sea salts.
\end{abstract}

\section{Hosted file}

Cui et al. Manuscript.docx available at https://authorea.com/users/303103/articles/433397high-level-epa-production-from-phaeodactylum-tricornutum

\section{Hosted file}

Cui et al. Manuscript-Figures.docx available at https://authorea.com/users/303103/articles/ 433397-high-level-epa-production-from-phaeodactylum-tricornutum 